\title{
PENERAPAN VALUE ENGINEERING PADA KONSTRUKSI DINDING PENAHAN TANAH DENGAN MENGGUNAKAN SITE MIX SEBAGAI PENGGANTI BENTONITE (STUDI KASUS PROYEK APARTEMEN DI SERPONG)
}

\author{
Sharwanda Asfarina', Chaidir Anwar Makarim² \\ ${ }^{1}$ Magister Teknik Sipil, Universitas Tarumanagara, Jakarta \\ Email: sharwandaasfarina@gmail.com \\ ${ }^{2}$ Magister Teknik Sipil, Universitas Tarumanagara, Jakarta \\ Email: chaidir259@gmail.com
}

Masuk: 05-11-2019, revisi: 13-01-2020, diterima untuk diterbitkan: 25-02-2020

\begin{abstract}
ABSTRAK
Dalam upaya memperoleh hasil desain yang efisien, stabil, dan optimal dengan mutu yang baik, salah satu metode analisis yang digunakan untuk mengevaluasi perencanaan proyek konstruksi adalah rekayasa nilai. Tujuan dari rekayasa nilai adalah penghematan biaya, optimalisasi kinerja, dan efisiensi waktu, tetapi tetap mempertimbangkan fungsi, kualitas, dan estetika proyek. Analisis rekayasa nilai dimulai dengan memilih salah satu kegiatan yang memiliki biaya lebih tinggi daripada aktivitas lainnya, kemudian analisis untuk menentukan klasifikasi alternative karya atau bahan dengan fungsi dasar dan sekunder sesuai dengan persyaratan dalam untuk mendapatkan biaya yang lebih baik. Pada analisis nilai ini bertujuan untuk memperoleh besarnya penghematan biaya yang dapat dilakukan pada pembangunan konstruksi setelah dilakukan Value Engineering dan menemukan keunggulan lebih di antara bahan Bentonite dan Site Mix. Site Mix dipilih untuk menggantikan bentonite dalam pekerjaan dinding penahan tanah. Penghematan yang didapatkan sebesar 10,4\% untuk pekerjaan bored pile dan 36,4\% untuk pekerjaan pengecoran. Berdasarkan hasil harga yang telah didapatkan, maka bisa diambil kesimpulan bahwa penggunaan site mix bisa memberikan penghematan yang jauh lebih besar dibandingkan dengan menggunakan bentonite. Baik dari analisis harga satuan pekerjaan di atas, ditemukan baik untuk pekerjaan pondasi bored pile secara keseluruhan maupun pekerjaan pengecoran saja dengan beton mutu K250, memberikan hasil bahwa penggunaan site mix akan lebih hemat. Selain menggunakan studi pustaka dan observasi, metode selanjutnya adalah survey kuisioner dengan menyebarkan pertanyaan-pertanyaan untuk diisi oleh para responden yang kemudian dimasukkan kedalam program SPSS lalu dilakukan uji validitas, uji reliabilitas, dan RII dari hasil kusioner tersebut didapatkan hasil yang mendukung bahwa site mix dapat digunakan sebagi pengganti bentonite dalam pekerjaan dinding penahan tanah.
\end{abstract}

Kata Kunci: Bentonite; Kuisioner; Site Mix; SPSS; Value Engineering

\begin{abstract}
In an effort to obtain efficient, stable, and optimal design results with good quality, one of the analytical methods used to evaluate construction project planning is value engineering. The purpose of value engineering is cost savings, performance optimization, and time efficiency, while still considering the function, quality, and aesthetics of the project. Value engineering analysis begins by selecting one activity that has a higher cost than other activities, then analysis to determine the alternative classification of works or materials with basic and secondary functions in accordance with the requirements in order to obtain better costs. In this value analysis aims to obtain the amount of cost savings that can be done in construction after the Value Engineering is done and find more advantages between Bentonite and Site Mix materials. Site Mix was chosen to replace bentonite in retaining wall works. The savings obtained were $10.4 \%$ for bored pile work and $36.4 \%$ for casting work. Based on the results of the prices that have been obtained, it can be concluded that the use of site mix can provide far greater savings compared to using bentonite. Both the analysis of the unit price of the above work, found both for the overall bored pile foundation work and casting work only with K250 quality concrete, giving the result that the use of site mix will be more efficient. In addition to using literature studies and observations, the next method is questionnaire survey by spreading questions to be filled in by respondents who are then included in the SPSS program and then tested for validity, reliability testing, and RII from the results of the questionnaire obtained results that support that the site mix can used as a substitute for bentonite in retaining wall works.
\end{abstract}

Keywords: Bentonite; Questionnaire; Site Mix; SPSS; Value Engineering 


\section{PENDAHULUAN}

\section{Latar Belakang}

Perusahaan kontruksi Indonesia dihadapkan pada persaingan yang berat, yaitu perusahaan kontruksi luar negeri dapat berkompetisi pada proyek-proyek nasional dan sebaliknya perusahaan konstruksi Indonesia juga dapat berkompetisi pada proyek luar negeri. Salah satu upaya untuk menjaga dan meningkatkan daya saing adalah dengan mempromosikan inovasi dalam industry konstruksi nasional. Inovasi diyakini memberikan manfaat bagi industri konstruksi.

Ketersediaan metode yang menyediakan teknik inovasi menjadi sangat penting untuk antisipasi persaingan yang ketat. Value engineering (VE) merupakan salah satu diantaranya. Beberapa penelitian yang telah dilakukan menunjukkan bahwa penerapan value engineering akan dapat mendorong munculnya ide-ide baru/inovasi dan meningkatkan daya saing dalam jangka panjang.

Penerapan VE pada bidang konstruksi merupakan suatu pendekatan yang dilakukan secara sistematis oleh tim dari banyak disiplin ilmu yang melakukan fokus pada nilai dan fungsi. Penerapan VE pada proyek konstruksi mempunyai potensi penghematan yang cukup besar dari anggaran biaya proyek. Penerapan VE yang dilakukan pada proyek konstruksi, teknik dan alternatif yang dipakai berbeda-beda, hal ini disebabkan karena pendekatan yang dipakai, kondisi budaya, dan sistem procurement yang berbeda. Ketidakefisienan pelaksanaan konstruksi bangunan gedung pada saat ini masih banyak terjadi,sehingga perlu dilakukan review design atau dilakukannya rekayasa nilai (value engineering) agar biaya-biaya dan usaha-usaha yang tidak diperlukan dapat dihilangkan atau direduksi sehingga nilai atau biaya proyek tersebut dapat lebih hemat lagi.

Seperti kasus yang terjadi pada proyek yang diteliti oleh penulis, yaitu proyek dengan menggunakan persetujuan harga kontrak berdasarkan luasan, yaitu harga per meter persegi namun dengan dengan ketentuan jika harga pada design yang sudah ada melebihi harga yang telah disepakati, maka kontraktor diberikan hak untuk mengajukan perubahan metode namun yang dapat menghemat atau menurunkan biaya tapi tidak mengurangi fungsi (fungsi sama atau lebih baik). Salah satu pekerjaan yang diajukan untuk perubahan design pada proyek ini adalah dinding penahan tanah. Sebagaimana diketahui dalam perkembangannya pembangunan gedung gedung bertingkat sering dihadapkan dengan kondisi struktur tanah yang tidak baik dan dilokasi yang sudah padat, sehingga perlu adanya sebuah rekayasa dalam usaha menjaga stabilitas tanah, agar proses konstruksi yang dilakukan tidak menimbulkan kerusakan dan kerugian. Dinding penahan tanah bertujuan agar mencegah keruntuhan tanah dikarenakan adanya proses penggalian pada proyek konstruksi, sehingga hal ini merupakan suatu rekayasa yang sangat diperlukan dan dilakukan pada masa awal tahap konstruksi, agar tahapan selanjutnya dapat dilakukan.

Pada perkembangannya konstruksi dinding penahan tanah banyak mengalami modifikasi dan inovasi baru, salah satunya bentonite dan site mix. Dimana keduanya memiliki keunggulan serta kekurangan baik secara metode, biaya dan waktu pengerjaannya. Maka hal ini sering menimbulkan perdebatan dalam menentukan mana yang lebih efektif dan efisien. Maka dalam hal ini perlunya sebuah proses value engineering untuk menilai jenis konstruksi mana yang lebih efektif dan efisien secara metode, biaya dan waktu pengerjaanya. 


\section{Rumusan Masalah}

Berdasarkan hasil penerapan value engineering dan analisis dari responden untuk pekerjaan dinding penahan tanah, apakah bahan bentonite dan bahan site mix mempunyai hasil yang sama ataukah diantaranya memiliki kenggulan lebih?

\section{Tujuan Penelitian}

Tujuan penelitian ini untuk memperoleh besarnya penghematan biaya yang dapat dilakukan pada pembangunan konstruksi setelah dilakukan value engineering serta menemukan diantara kedua bahan tersebut yang memiliki keunggulan lebih pada penggunaannya.

\section{METODE PENELITIAN}

Metode penelitian adalah suatu tahapan yang dicapai dalam menulis sebuah karya ilmiah. Metode penelitian diperlukan agar penelitian yang dilakukan dapat ditulis secara urut, tertata dan sistematis. Metode penelitian berisikan tahap tahap penelitian yang dilalui dari penulisan pendahuluan hingga penyusunan hasil penelitian.

Pada penelitian ini penulis menggunakan data primer dan data sekunder, data primer dalam penelitian ini berupa kuesioner. Penulis akan memberikan seperangkat pertanyaan kepada responden mengenai penelitian dalam tulisan ini, dengan responden yang dimaksud adalah kontraktor, konsultan pengawas, serta pihak pemilik proyek. Data sekunder yang juga digunakan untuk penelitian ini adalah harga - harga dan indeks pekerjaan yang diperlukan untuk analisis harga satuan pekerjaan menggunakan bentonite dan site mix. Data sekunder lainnya yang digunakan adalah tabel penjadwalan rencana awal yang menggunakan bentonite dan table penjadwalan akhir yang menggunakan site mix serta data tanah proyek tersebut. Kemudian menggunakan cara value engineering dengan bantuan MS. Excel. Pengolahan data primer dilakukan dengan mengumpulkan data hasil kuesioner, lalu dilakukan uji validitas dan reliabilitas sebelum dilakukan analisis dengan RII (Relative Importance Index). Untuk data sekunder akan dianalisis melalui cara analisis harga satuan pekerjaan yang didasarkan dengan SNI 2008 dan PERMEN 28/PRT/M/2016.

Data - data yang didapat akan dianalisis menggunakan bantuan program SPSS dan Ms Excel. Rumus umum yang digunakan untuk analisis dengan bantuan program tersebut antara lain sebagai berikut:
a. Spearman - Brown
b. Cronbach's Alpha
c. RII (Relative Importance Index)

Perhitungan rumus - rumus 1 dan 2 di atas akan dilakukan dengan bantuan program SPSS, sedangkan rumus 3 akan dianalisis dengan bantuan MS. Excel.

\section{HASIL DAN PEMBAHASAN Tahap Analisis Fungsi}

Pada tahap ini ada 2 hal yang akan kita bahas yaitu Function Analysis System Technique (FAST) Diagram dan Functional Analysis. 


\section{FUNCTION ANALYSIS SYSTEM TECHNIQUE (FAST) DIAGRAM}

Function Analysis System Technique (FAST) Diagram adalah salah satu tools yang digunakan untuk menganalisis fungsi produk dalam value analysis. Melalui FAST Diagram ini, semua fungsi produk dapat tersusun secara skematis.

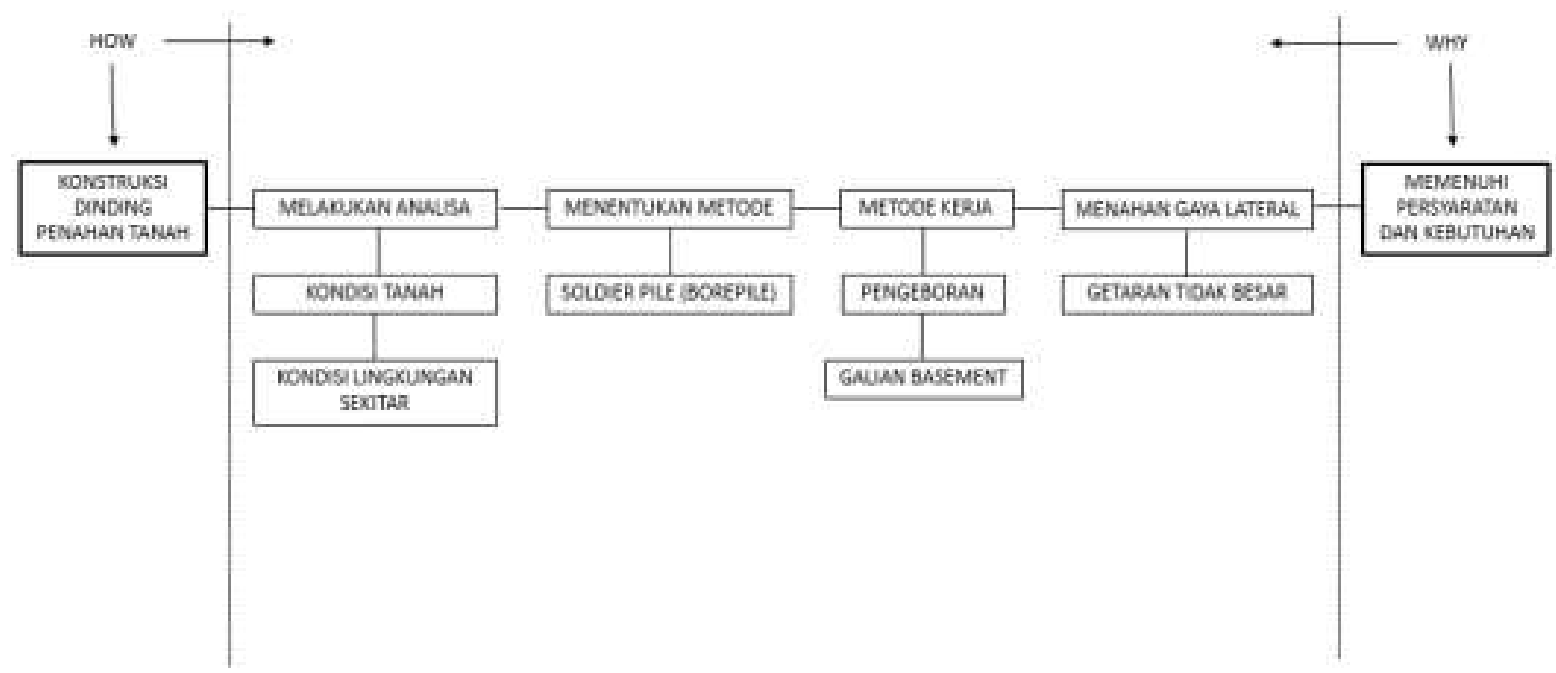

Gambar 2. Function Analysis System Technique (FAST) Diagram dinding penahan tanah proyek apartemen area Serpong

Pada Gambar 2 dapat dilihat bahwa area proyek berada pada daerah pemukiman warga sehingga metode yang dipilih untuk pekerjaan dinding penahan tanah adalah konstruksi soldier pile (barisan bored pile) karena dengan fungsi sebagai dinding penahan tanah (menahan gaya lateral), getaran yang dihasilkan selama proses pekerjaan pengeboran tiang tidak terlalu besar sehingga tidak mengganggu lingkungan sekitar. Alasan lain mengapa digunakan dinding penahan tanah pada proyek ini yaitu lapisan tanah di atas basement terindikasi highly expansive. Dilihat dari Plasticity indexnya yang lebih besar dari $30 \%$. Artinya terdapat tekanan lateral tambahan.

\section{SUMMARY OF LABORATORY TEST RESULT}

\begin{tabular}{|c|c|c|c|c|c|}
\hline \multicolumn{6}{|c|}{ Sample No. } \\
\hline \multicolumn{3}{|c|}{ Bore Hole No. } & DB 1 & DB 1 & DB 1. \\
\hline \multicolumn{3}{|c|}{ Sample Depth } & $1.00-1.50$ & $19.50-20,00$ & $21.50-22.00$ \\
\hline \multirow{4}{*}{ 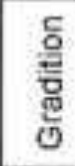 } & Gravel & $\%$ & & & \\
\hline & sand & $\%$ & 9.28 & 0.86 & 2.76 \\
\hline & Silt & $\%$ & 32.22 & 53.14 & 48.24 \\
\hline & Clay & $\%$ & 58.50 & 46.00 & 49.00 \\
\hline \multicolumn{2}{|c|}{ Liquit Limit } & $\%$ & 83.40 & 81.20 & 72.20 \\
\hline \multicolumn{2}{|c|}{ Plastic Limit } & $\%$ & 38.51 & 36.03 & 28.75 \\
\hline \multicolumn{2}{|c|}{ Plasticity indeks } & $\%$ & 46.89 & 45.17 & 43.45 \\
\hline
\end{tabular}

Gambar 3. Hasil tes laboratorium

Pada data Boring log dibawah ini juga menjelaskan posisi MAT (muka air tanah) pada proyek Area Serpong tersebut. 


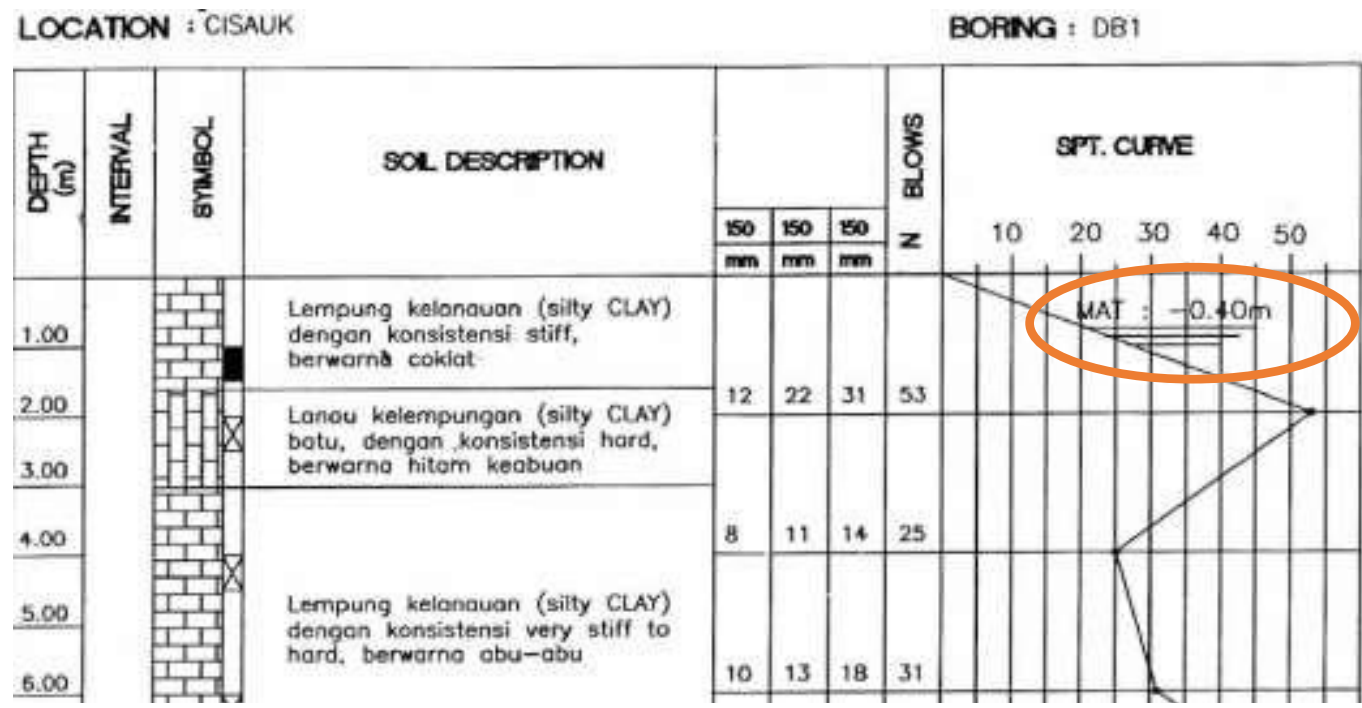

Gambar 4. Hasil boring log

Pada data Boring log perbulan November di atas didapatkan bahwa muka air tanah pada ketinggin $0 \mathrm{~m}-5 \mathrm{~m}$ ada pada elevasi $-0,4$ dari permukaan tanah. Jadi di bulan Januari/Februari yang merupakan puncak musim hujan MAT penuh dan ketinggian air sungai yang berada langsung bersebelahan dengan DPT meningkat. Berarti tekanan tanah lateral aktif solid full dan bertambah $25 \%$. Dengan berbagai kondisi tersebut maka diperlukan konstruksi dinding penahan tanah pada proyek area Serpong.

\section{Analisis Harga Satuan Pekerjaan (AHSP)}

Analisis harga satuan pekerjaan berikut mengacu pada SNI 2008 dan PERMEN 28/PRT/M/2016 Berdasarkan hasil analisis yang telah dilakukan berdasarkan cara analisis harga satuan pekerjaan (AHSP), maka bisa dikatakan bahwa pekerjaan menggunakan bentonite akan lebih mahal dibandingkan dengan menggunakan site mix. Perbandingan harga yang didapat cukup besar, dengan pekerjaan bored pile menghemat $10,4 \%$ biaya dan pekerjaan pengecoran menghemat biaya sebesar $36,4 \%$ bila menggunakan site mix dibandingkan dengan bentonite.

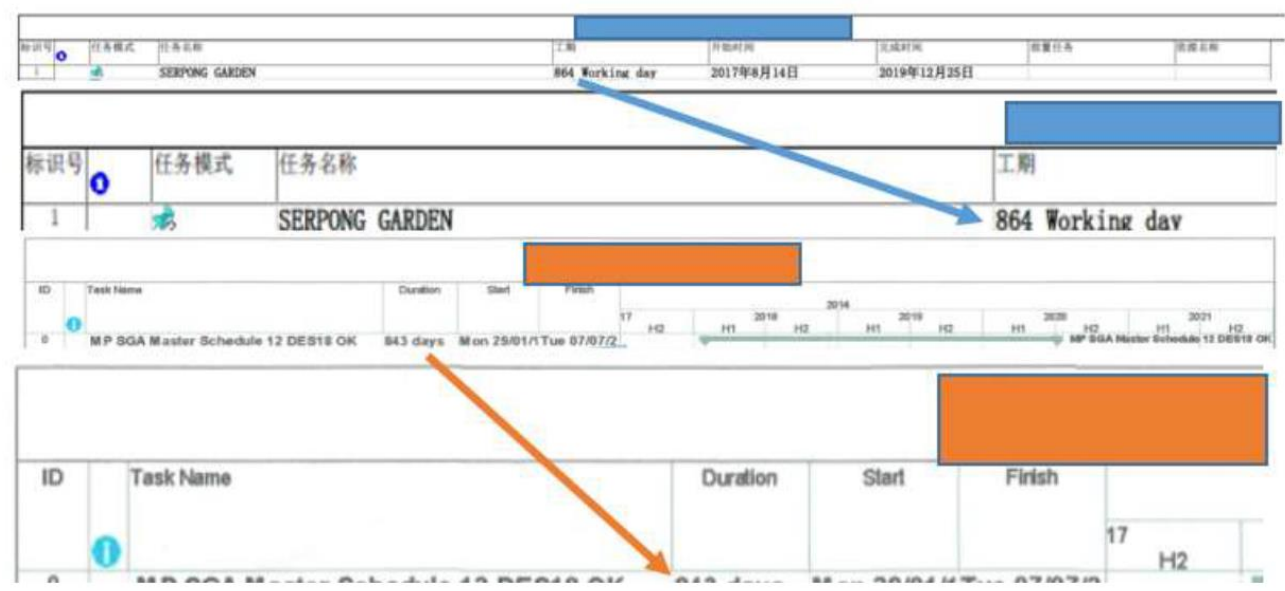

Gambar 5. Master schedule dari proyek (Atas/ Biru: Penggunaan bentonite; Bawah/ Oranye:

Sumber : Penulis, 2019 
Berdasarkan gambar yang bisa dilihat di atas, jadwal dengan rencana penggunaan bentonite akan menghasilkan waktu yang lebih lama dibandingkan dengan rencana penggunaan site mix, hal ini menunjukkan bahwa penggunaan site mix akan memberikan salah satu keuntungan lebihnya adalah pekerjaan yang bisa diselesaikan lebih cepat.

\section{Analisis Kuisioner}

Tahap ini merupakan tahap pengumpulan data - data dari hasil kuesioner yang telah dijawab oleh responden yang telah di tentukan, kemudian di olah dengan bantuan SPSS (Statistical Package for The Social Sciences). hasil pengisian kuesioner menghasilkan data responden sebanyak 30 responden yang bekerja dalam bidang konstruksi khususnya konstruksi bangunan gedung tinggi (High Rise Building). Karakteristik responden dalam penelitian ini dapat dilihat dari segi pendidikan, jabatan dan masa kerjanya di instansi kerja masing - masing responden.

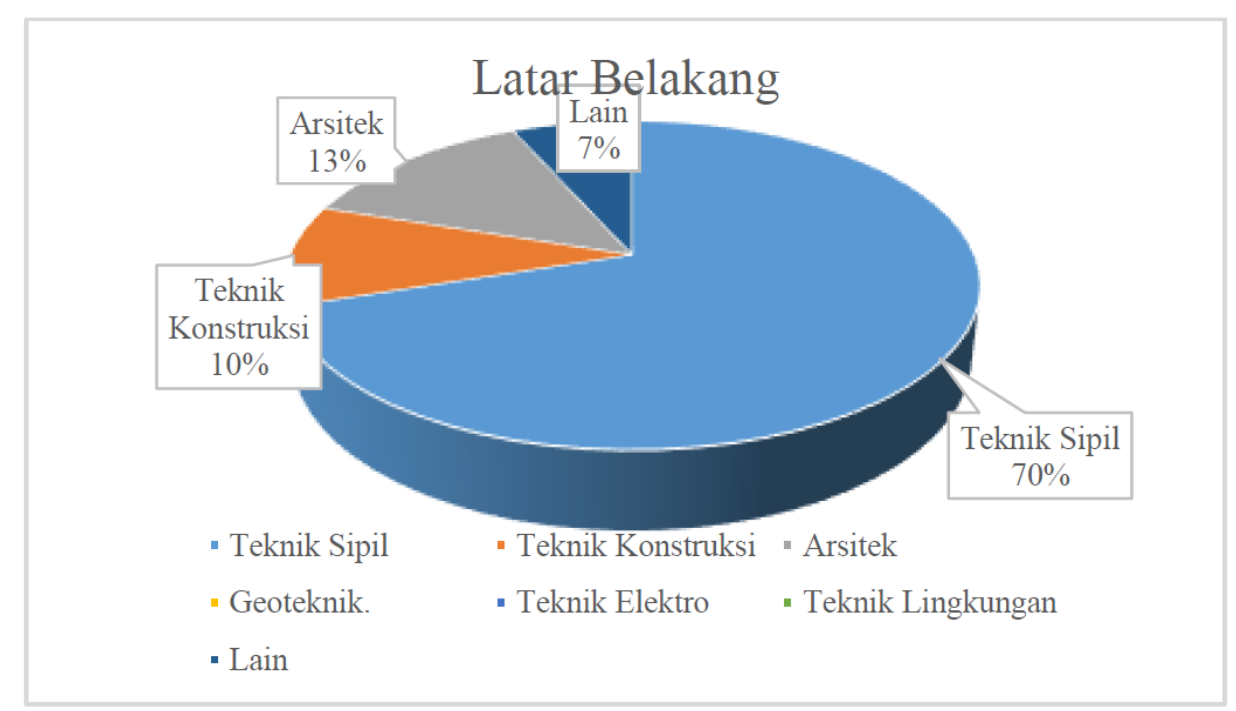

Gambar 6. Grafik latar belakang responden Sumber : Penulis, 2019

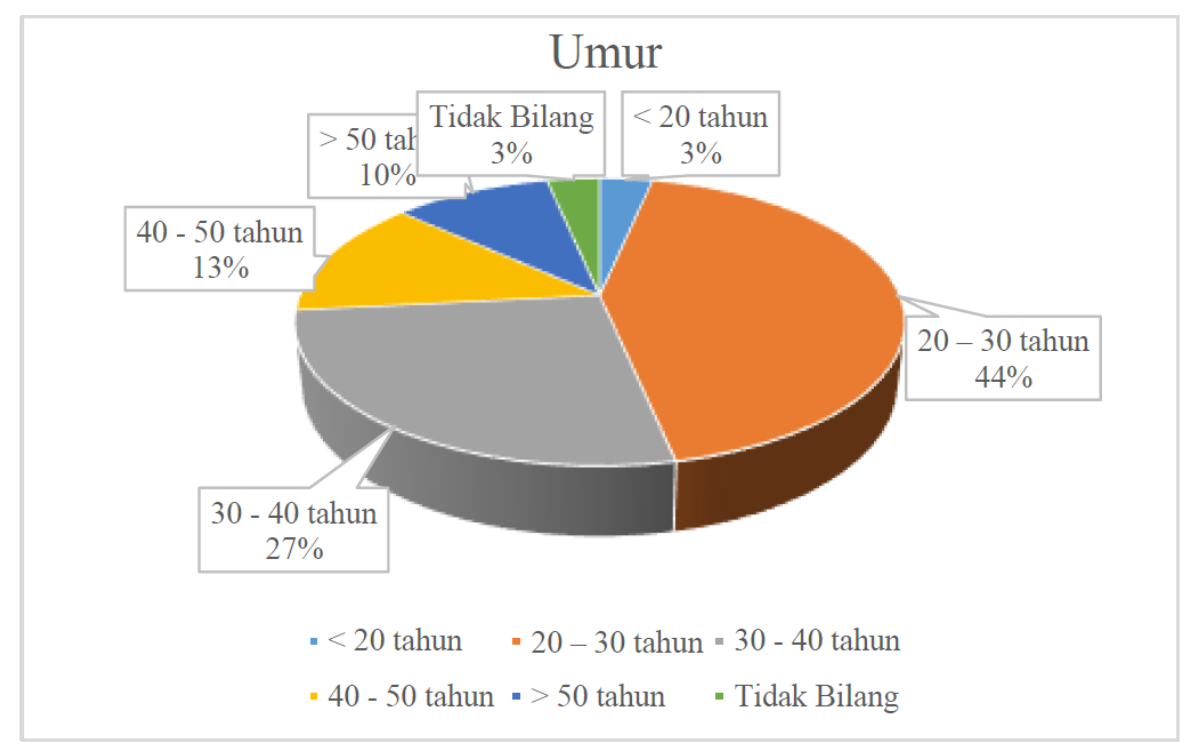

Gambar 7. Grafik umur responden Sumber : Penulis, 2019 


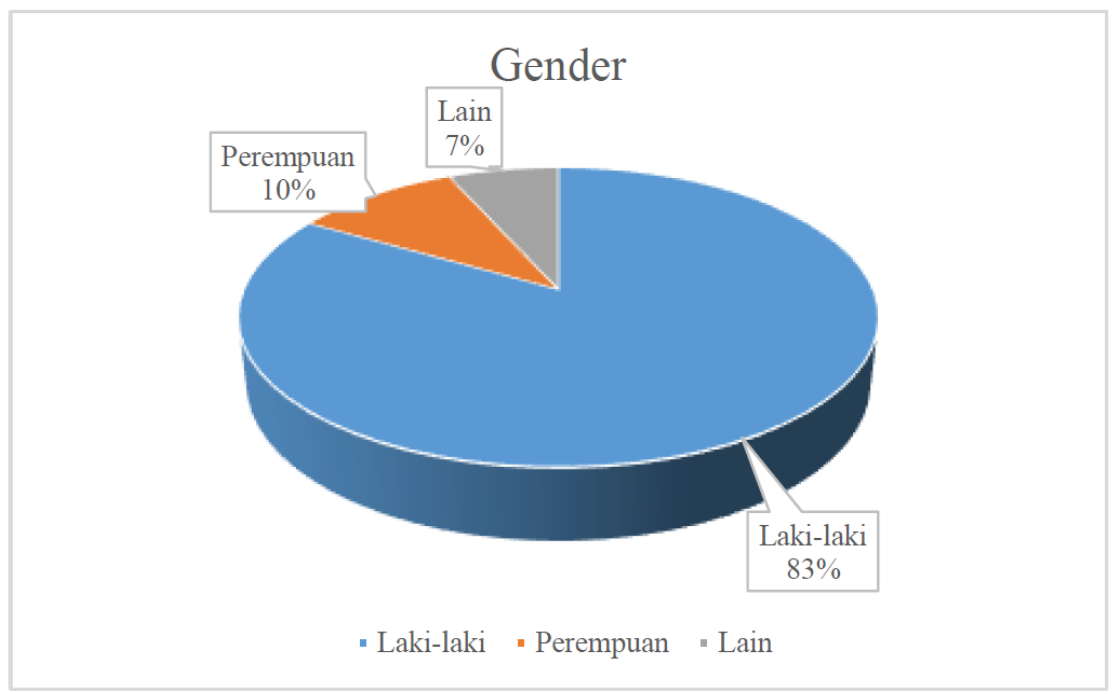

Gambar 8. Grafik jenis kelamin responden

Sumber : Penulis, 2019

\section{VARIABEL KUESIONER}

Berikut adalah daftar pertanyaan kuesioner yang diajukan kepada responden. Variabel Q1-Q8 adalah pertanyaan mengenai bahan-bahan kerja (material), variable Q9-Q23 adalah pertanyaan mengenai metode kerja, dan variable Q24-Q31 adalah pertanyaan mengenai waktu pelaksanaan.

Tabel 1 Variabel Pertanyaan

\begin{tabular}{|c|c|c|c|c|c|}
\hline No & \multicolumn{2}{|l|}{ Variabel Pertanyaan } & Q18 & Bagaimana menjaga mutu dalam pelaksanaan pekerjaan & \\
\hline Q1 & Apakah Bahan Baku Mudah DIdapat? & \multirow{8}{*}{$\begin{array}{c}\text { Bahan } \\
\text { Baku }\end{array}$} & & & \\
\hline Q2 & Bagaimana Dengan harga bahan baku? & & Q19 & Bagaimana menjaga mutu dari pekerjaan tersebut? & \\
\hline Q3 & Berapa lama bahan baku dapat sampai dilokasi? & & Q20 & $\begin{array}{l}\text { Apakah perlu peralatan khusus untuk menjaga mutu yang } \\
\text { diinginkan? }\end{array}$ & \\
\hline Q4 & Bagaimana cara merawat bahan baku? & & Q21 & $\begin{array}{l}\text { Apakah perlu pekerjaan tambahan untuk meningkatkan } \\
\text { mutu tersebut? }\end{array}$ & \\
\hline Q5 & Berapa lama bahan baku dapat disimpan? & & & Apakah pekerjaan tersebut dapat dilakukan bersamaan & \\
\hline Q6 & Apakah ada tambahan bahan lain yang diperlukan? & & Q22 & dengan pekerjaan yang lain? & \\
\hline Q7 & Apakah bahan baku perlu tempat penyimpanan khusus? & & Q23 & $\begin{array}{l}\text { Apakah hasil yang dicapai sesuai dengan yang } \\
\text { direncanakan? }\end{array}$ & \\
\hline Q8 & Apakah kondisi cuaca mempengaruhi mutu? & & 024 & Berapa lama waktu yang diperlukan dalam menyelesaikan & \\
\hline Q9 & Apakah mudah dikerjakan? & & & pekerjaan tersebut? & \\
\hline Q10 & Apakah memerlukan tenaga kerja ahli teknik khusus? & & Q25 & $\begin{array}{l}\text { Apakah faktor alat mempengaruhi waktu pelaksanaan } \\
\text { pekerjaan tersebut? }\end{array}$ & \\
\hline Q11 & $\begin{array}{l}\text { Apakah pekerjaan ini dapat dilakukan dalam semua kondisi } \\
\text { cuaca? }\end{array}$ & & Q26 & $\begin{array}{l}\text { Apakah jumlah pekerja mempengaruhi waktu untuk } \\
\text { menyelesaikan pekerjaan tersebut? }\end{array}$ & \\
\hline Q12 & Apakah perlu suatu alat khusus dalam pelaksanaannya? & & Q27 & $\begin{array}{l}\text { Apakah kondisi lingkungan mempengaruhi waktu } \\
\text { pekerjaan? }\end{array}$ & Waktu \\
\hline Q13 & Bagaimana bila dilakukan pada kondisi lokasi yang sempit? & & & & \\
\hline Q14 & $\begin{array}{l}\text { Apakah pekerjaan dapat dilakukan oleh pekerja yang belum } \\
\text { berpengalaman? }\end{array}$ & & Q28 & pekerjaan? & \\
\hline Q15 & Berapa banyak pekerja yang dibutuhkan? & & Q29 & $\begin{array}{l}\text { Berapa lama waktu yang diperlukan agar mutu pekerjaan } \\
\text { tercapai? }\end{array}$ & \\
\hline Q16 & $\begin{array}{l}\text { Apakah perlu banyak tahapan dalam penyelesaian } \\
\text { pekerjaan tersebut? }\end{array}$ & & Q30 & $\begin{array}{l}\text { Apakah kondisi tanah mempengaruhi waktu pelaksanaan } \\
\text { pekerjaan? }\end{array}$ & \\
\hline Q17 & $\begin{array}{l}\text { Apakah tahapan-tahapan dalam pekerjaan tersebut dapat } \\
\text { dilakukan secara bersamaan? }\end{array}$ & Metode & Q31 & $\begin{array}{l}\text { Berapa lama pelaksanaan pekerjaan pada kondisi muka air } \\
\text { tanah yang tinggi? }\end{array}$ & \\
\hline
\end{tabular}

\section{UJI VALIDITAS}

Uji validitas dilakukan untuk menguji valid atau tidaknya variabel - variabel yang merupakan pertanyaan pada responden kuisioner didapatkan 30 orang dan uji validitas dilakukan dengan rumus Spearman-Brown untuk skala ordinal. Variabel dinyatakan valid bila nilai koefisien Corrected Item- Total Correlation hasil perhitungan lebih besar dari 0,306. untuk $\mathrm{n}=30$ dengan tingkat signifikansi sebesar 0,05 , bila nilai koefisien pada tabel Corrected Item- Total Correlation tidak mencapai 0,306 maka variable dinyatakan tidak valid. 
Dari hasil uji validitas menunjukkan bahwa nilai koefisien untuk masing-masing pertanyaan memiliki nilai koefisien lebih dari 0,306 maka bisa disimpulkan bahwa pertanyaan-pertanyaan pada kuisioner sudah valid untuk responden berjumlah 30 dengan signifikansi 0,05 .

\section{UJI RELIABILITAS}

Dengan menggunakan bantuan program SPSS, tabel berikut ini adalah hasil uji reliabilitas dari kedua komponen faktor yang terbentuk :

Tabel 2. Nilai Cronbach's Alpha pekerjaan menggunakan bentonite

\begin{tabular}{cc}
\hline Cronbach's Alpha & Nof Items \\
\hline .919 & 25 \\
\hline
\end{tabular}

Sumber: Hasil analisis, 2018

Dari tabel 2 menunjukkan bahwa hasil analisis nilai Cronbach's alpha untuk pekerjaan menggunakan bentonite masuk dalam kategori "Sangat Reliabel”.

Nilai Cronbach's Alpha kuesioner bahan site mix

Tabel 3. Nilai Cronbach's Alpha pekerjaan menggunakan sitemix

\begin{tabular}{cc}
\hline Cronbach's Alpha & Nof Items \\
\hline .950 & 28
\end{tabular}

Sumber: Hasil analisis, 2018

Dari tabel di atas menunjukkan bahwa hasil analisis nilai Cronbach's Alpha untuk pekerjaan menggunakan site mix sama dengan pekerjaan menggunakan bentonite yaitu masuk dalam kategori "Sangat Reliabel”.

\section{ANALISIS HASIL RELATIVE IMPORTANCE INDEX (RII)}

Berikut adalah hasil RII (Relative Importance Index) dari masing masing pekerjaan yaitu bentonite dan site mix yang telah dikelompokkan variabel-variabelnya sebagai berikut :

a. Q1-Q8 adalah pertanyaan mengenai Bahan Baku Pekerjaan

b. Q9-Q23 adalah pertanyaan mengenai Metode Pekerjaan

c. Q24-Q31 adalah pertanyaan mengenai Waktu Pekerjaan

untuk pekerjaan dengan menggunakan bentonite didapatkan hasil sebagai berikut :

a. Variabel untuk bahan baku pekerjaan didapatkan RII dengan nilai paling besar ada di urutan pertama (1) adalah Q3A yaitu sebesar 0,7083

b. Variabel untuk metode pekerjaan didapatkan RII dengan nilai paling besar ada di urutan pertama (1) adalah Q10 yaitu sebesar 0,7167

c. Variabel untuk waktu pekerjaan didapatkan RII dengan nilai paling besar ada di urutan pertama (1) adalah Q27 yaitu sebesar 0,6917

Berarti dalam hal penggunaan bentonite maka dari sisi bahan baku, maka cepatnya bahan baku bisa sampai ke lokasi tujuan adalah variabel utama dalam penggunaan bentonite, untuk metode pekerjaan, maka penggunaan tenaga kerja dengan keahlian yang khusus adalah variabel utama dalam memilih bentonite sebagai material pengecoran yang artinya diperlukan tenaga kerja dengan edukasi dan praktis yang mencukupi dalam pekerjaan ini, untuk waktu pengerjaan maka 
kondisi lingkungan merupakan salah satu variabel utama dalam penggunanan bentonite, dimana cuaca sangat berpengaruh dalam penggunaan dan durasi pekerjaan dengan bentonite.

Untuk pekerjaan dengan menggunakan site mix didapatkan hasil sebagai berikut :

a. Variabel untuk bahan baku pekerjaan didapatkan RII dengan nilai paling besar ada di urutan pertama (1) adalah Q1B yaitu sebesar 0,7583 dan Q3B yaitu sebesar 0,7583

b. Variabel untuk metode pekerjaan didapatkan RII dengan nilai paling besar adalah Q23B yaitu sebesar 0,7333

c. Variabel untuk waktu pekerjaan didapatkan RII dengan nilai paling besar ada di rurutan pertama (1) adalah Q26B yaitu sebesar 0,667.

Berarti dalam hal penggunaan site mix dalam pekerjaan dinding tanah, dalam hal bahan ditemukan bahwa kemudahan didapatkannya bahan dan kecepatan bahan baku sampai kelokasi merupakan variabel utama alasan responden memilih bahan ini, untuk metode ditemukan bahwa hasil danrencana dapat dicapai dengan baik merupakan variabel utama kenapa responden menggunakan site mix, dan untuk waktu ditemukan bahwa semakin banyak pekerja yang ada maka pekerjaan akan semakin cepat selesai, berarti semakin banyak tukang yang mempunyai kompentensi tinggi berarti pekerjaan akan selesai dengan lebih cepat.

\section{KESIMPULAN DAN SARAN}

\section{Kesimpulan}

Pekerjaan Bored Pile jika menggunakan Site Mix dapat menghemat biaya dibandingkan dengan menggunakan bentonite. Maka dari hasil - hasil yang telah didapat bisa disimpulkan bahwa penggunaan Site Mix dibandingkan Bentonite pada proyek ini merupakan keputusan yang tepat dan bisa memberikan hasil yang lebih murah dengan hasil yang lebih baik. Melalui responden juga ditemukan bahwa sebagian besar dari narasumber lebih memilih dan memiliki respon positif terhadap penggunaan Site Mix dibandingkan dengan Bentonite dari pertanyaan pertanyaan yang ada, responden menjawab positif (yaitu skala Likert yang dipilih adalah antara 3 dan 4) lebih banyak terhadap penggunaan Site Mix dibandingkan dengan Bentonite. Berdasarkan hal ini maka bisa disimpulkan bahwa dalam pekerjaan dinding penahan tanah dimana penelitian ini dilakukan, penggunaan Site Mix jauh lebih dipilih dibanding dengan Bentonite.

\section{Saran}

a. Penelitian yang serupa bisa dijalankan lagi pada lokasi proyek yang berbeda.

b. Penelitian berikutnya dapat mencantumkan spesifikasi bangunan atau konstruksi yang dapat menggunakan konstruksi dinding penahan tanah dengan Bentonite atau Site Mix.

c. Penelitian serupa dapat menyertakan perhitungan kekuatan struktur untuk masing-masing metode pekerjaan dinding penahan tanah (Bentonite dan Site Mix).

\section{REFERENSI}

Antoni dan Nugraha, Paul. (2007): Teknologi Beton. Penerbit C.V Andi Offset, Yogyakarta. ASTM C 618-92a Standard Specification of Pozzolan. United States: ASTM

Barrie, Donald S, Paulson Jr, Boyd C. (1984): Professional Construction Management. New York: McGraw-Hill, Inc.

Bowles, J. E. (1971): Foundation Analysis and Design. Tokyo, Japan: McGrawHill Kogakusha, Ltd. 
Caduto, Donald P. (2001): Foundation Design-Principles and Practice, Prentice-Hall.inc, New Jersey.

Donomartono. (1999): Apilkasi Value Engineering Guna Mengoptimalkan Biaya pada Tahap Perencanaan Kontruksi Gedung dengan Struktur Balok Beton Pratekan. Tugas Akhir JTS. Surabaya: Fakultas Teknik Institut Teknologi Sepuluh Nopember.

Emzir. (2010): Metodologi Penelitian Kualitatif: Analisis Data. Jakarta: PT Raja Grafindo Persada.

Gasperz, Vincent. (1989): Statistika. Armico:Bandung

Hutabarat, J. (1995): Diktat Rekayasa Nilai (Value Engineering). Malang: Institut Teknologi Nasional.

Hardiyatmo, H. C. (2009): Pemeliharaan Jalan Raya: Perkerasan, Drainase, Longsoran. Yogyakarta: Gadjah Mada University Press.

Hardiyatmo, Hary Christady. (2015): Analisa dan Perancangan Fondasi II (edisi ketiga). Gadjah Mada University Press. Yogyakarta.

Hardjomuljadi, Sarwono. (2014): Factor Analysis on casual of construction Claims and Disputes in Indonesia (with reference to the construction of hydroelectric power project in Indonesia), International Journal of applied Engineering Research, ISSN 0973-4562, Volume 9, November 22, pp. 12421-12445.

Hartono. (2011): Metodologi Penelitian. Pekanbaru: Zanafa Publishing.

Hasan, Iqbal. (2002): Metodologi Penelitian. Jakarta: Ghalia Indonesia.

Hasan, Iqbal. (2006): Analisis data Penelitian Dengan Statistik. Jakarta: Bumi Aksara

Herdiman, L. L., Liquiddanu, E., \& Paramita, D. (2011): Perbaikan Rancangan Pada Desain Knee Ankle Foot Orthosis (Kafo) Dengan Pendekatan Metode Function Analysis System Technique.J@ TI UNDIP: JURNAL TEKNIK INDUSTRI, 6(3), 189-198.

Kementrian Pekerjaan Umum Perumahan Rakyat, (2016): Permen PUPR No.28/PRT/M/2016, Tentang Pedoman Analisis Harga satuan Pekerjaan Bidang Pekerjaan Umum.

Makarim, Chaidir Anwar. (2007): VE Teori (Terjemahan Bebas) Buku Instruktur. GDLN (GLAD Batch 3) Value Engineering e-learning 2007 module

Miles, Lawrence. (1961): Techniques Of Value Analisys And Engineeri. New York.

Montgomery, D. C., \& Runger, G. C. (2003): Applied statistics and probability for engineers. (3th ed.). New York: John Wiley \& Sons, Inc.

Montgomery, D. C. (2005): Introduction to statistical quality control. (5th ed.). Hoboken, New Jersey: John Wiley \& Sons, Inc.

Mulyono, Tri. (2003): Teknologi Beton, Penerbit ANDI Yogyakarta.

Munaf, D.R. (2002): “Material Semen dan Beton (SI-487)”, Penerbit ITB, Bandung.

Narbuko, Cholid \& Achmad, Abu. (2008): Metodologi Penelitian. Jakarta: Bumi Aksara

Nasir, Mohammad. (1988): Metode Penelitian. Cet.3. Jakarta: Ghalia Indonesia, 1988

Nelson, L. S. (1988): Control charts: rational subgroups and effective applications. Journal of Quality Technology, 20(1), 73-75.

Peraturan Menteri Pekerjaan Umum dan Perumahan Rakyat Nomor : 28/Prt/M/2016 (Permen 28/PRT/M/2016) Tentang Analisis Harga Satuan Pekerjaan Bidang Pekerjaan Umum

Prins, J. (2006): Proportions control charts. In NIST \& SEMATECH (Eds.), e-Handbook of Statistical Methods (chap. 6.3.3.2).

Pusat Penelitian dan Pengembangan Teknologi Mineral dan Batubara. (2005). Bentonit diambil dari $\quad$ http://www.tekmira.esdm.go.id/data/Bentonit/ulasan.asp?xdir=Bentonit\&commI $=8 \& \mathrm{comm}=$ Bentonit pada 21 April 2015 .

Sajekti, Amien. (2013): Metode Kerjan Bangunan Sipil-Edisi Pertama. Yogyakarta. Graha Ilmu. Sardjono, H.S. (1988): Pondasi Tiang Pancang (Jilid 1), Penerbit Sinar Jaya Wijaya, Surabaya. 
Sarwono. (2012): Metode Riset Skripsi Pendekatan Kuantitatif Menggunakan Prosedur SPSS. Jakarta: Media Elex Komputindo.

Sekaran, U. (2006): Metode Penelitian Untuk Bisnis 1. (4th ed).Jakarta: Salemba Empat.

Singarimbun, Masri \& Effendi, Sofian. (1987): Metode Penelitian Survai. Jakarta: LP3ES.

SNI 2836-2008. Tata cara perhitungan harga satuan pekerjaan pondasi untuk konstruksi bangunan gedung dan perumahan. Badan Standarisasi Nasional.

SNI 7394-2008. Tata cara perhitungan harga satuan pekerjaan beton untuk konstruksi bangunan gedung dan perumahan. Badan Standarisasi Nasional.

Somantri, Ating dan Sambas Ali Muhidin, (2006): Aplikasi Statistika dalam penelitian. Pustaka ceria : Bandung

Sower, V. E. (2011): Essentials of quality with cases and experiential exercises. Hoboken, New Jersey: John Wiley \& Sons, Inc.

Soeharto, Iman. (1995): Manajemen Proyek. Jakarta: Erlangga.

SNI 8073 (2016): Metode Uji Penentuan kadar pasir Dalam Slari Bentonit

Sudjana. (2001): Metode Statistika, Edisi Revisi, Cet. 6, Bandung: Tarsito

Sugiyono. (2006): Metode Penelitian Kuantitatif Kualitatif dan R\&D. Bandung: Alfabeta.

Sukandarrumidi. (2002): Metodologi Penelitian. Yogyakarta: Gadjah Mada Univercity Press

Wesley, Laurence D. (2010): Mekanika Tanah, Penerbit Andi, Yogyakarta.

Zainal dan Respati, Sri. (1995): Pondasi. Pusat Pengembangan Pendidikan Politeknik Bandung. Bandung.

Zimmerman. L.W, Hart. G.D. (1982): Value Engineering, A Practical Approach for Owner, Designers and Contractors. Edisi 14. New York, USA: Van Nostrand Reinhold Company. 
